\title{
Reaction time to a tone in noise as a function of the signal-to-noise ratio and tone level
}

\author{
SIMON KEMP \\ University of Canterbury, Christchurch, New Zealand
}

\begin{abstract}
Reaction time to the onset of a $1-\mathrm{kHz}$ tone against a background of continuous noise was investigated. Results showed reaction time to decrease with increasing tonal level, even when the signalto-noise ratio was held constant, implying that Weber's law does not hold for reaction time to a tone in noise. When the reaction times were plotted against the loudness of the tone, determined independently in a second experiment, no simple relationship emerged, contrary to the hypothesis that reaction time to a sound is a simple function of its loudness. It is concluded that reaction time processes differ from the processes involved in loudness discrimination or in signal detection.
\end{abstract}

It is well established that the time taken to react to a sound decreases as the intensity of the sound is increased. The result has been found to hold not only for sounds in the quiet (e.g., Chocholle, 1940; Santee \& Kohfeld, 1977; Kohfeld, Santee, \& Wallace, 1981), but also for sounds presented in a variety of noisy and tonal backgrounds (e.g., Chocholle \& Greenbaum, 1966; Emmerich, Pitchford, \& Becker, 1976; Kemp \& Irwin, 1979; Raab \& Grossberg, 1965).

Various models have been proposed to explain, and occasionally to predict quantitatively, the dependence of reaction time on stimulus intensity. Often the underlying process has been assumed to comprise two serial processes: a sensory and decision-making stage and a second, response-initiation stage (e.g., Kemp \& Irwin, 1979; Kohfeld et al., 1981; Luce \& Green, 1972). It is usually thought that the relationship of reaction time to intensity arises from the sensory and decision stage.

Probably the simplest hypothesis that can be made regarding the critical sensory and decision stage is that it operates in the same way for reaction time as for auditory threshold experiments. Under this hypothesis, wellestablished results from the threshold experiments should have counterparts in reaction time experiments. It is wellknown that Weber's law describes rather well the auditory threshold of a tone in noise (Hawkins \& Stevens, 1950): for a wide range of stimulus levels, the detectability of the tone is unaffected by variation of tone and noise levels, provided the ratio of signal power to noise power is held constant. Thus, if the sensory and decision process used in reaction time experiments is the same as that used in detection experiments, reaction time

The research was partially supported by the National Acoustics Centre and by the Medical Research Council of New Zealand. My thanks are also due Murray Simmonds, for useful discussions of the research, and the anonymous reviewers, for their constructive criticism of an earlier draft of the paper. The author's mailing address is: Department of Psychology, University of Canterbury, Christchurch 1, New Zealand. to a tone embedded in noise ought to be unaffected by noise and signal levels provided the signal-power-to-noisepower ratio is maintained.

An alternative hypothesis predicts a different outcome to the suggested experiment. According to this hypothesis, advanced by Chocholle (Chocholle, 1940, 1975; Chocholle \& Da Costa, 1971; Chocholle \& Greenbaum, 1966), reaction time to a sound is determined by the loudness of the sound. As, for example, a $60-\mathrm{dB}$ SPL tone partially masked by a $60-\mathrm{dB}$ noise sounds louder than a 50-dB tone partially masked by a 50-dB noise when other parameters are held constant (Scharf, 1964; Stevens \& Guirao, 1967; Zwicker, 1963), the 60-dB tone in this case should be reacted to faster than the $50-\mathrm{dB}$ tone.

\section{EXPERIMENT 1}

\section{Method}

Subjects. Eleven subjects served in the experiment. All had normal hearing and were paid for their participation.

Apparatus. White noise was generated and low-pass filtered $\left(f_{c}=\right.$ $7000 \mathrm{~Hz}$ ) before electronic mixture with the tone. A $1000-\mathrm{Hz}$ tone was produced by a signal generator and fed into a Grason-Stadler $829 \mathrm{E}$ electronic switch with a rise time of $5 \mathrm{msec}$. The output of the switch was mixed with the noise. Thus, the noise was on continuously while the tone signal could be turned on and off. The sound was attenuated to the desired level and presented to the subject monaurally through a TDH49 earphone. Subjects were seated in a sound-attenuating chamber where they responded by pressing a telegraph key with the preferred hand. The time taken to react to the onset of the tone was recorded on an electronic counter connected to the electronic switch and telegraph key.

Procedure. The subjects listened to the sound with the preferred ear. They were requested to respond as quickly as possible by depressing the telegraph key to the onset of the tone.

Two stimulus parameters, the level of the tone and the level of the white noise, were varied in the experiment. In the first part of the experiment, noise and signal levels were varied together to keep the signalpower-to-noise-power ratio constant at either -10 or $+10 \mathrm{~dB}$. Using the lower signal-to-noise ratio, the tone levels were $20,30,40,50$, and $60 \mathrm{~dB}$ SPL; the respective noise levels were $30,40,50,60$, and $70 \mathrm{~dB}$ SPL. For the $+10-\mathrm{dB}$ signal-to-noise ratio, the tone levels were 30 , $40,50,60$, and $70 \mathrm{~dB}$ SPL and the respective noise levels of 20,30 , 40,50 , and $60 \mathrm{~dB}$ SPL. In the second part of the experiment, the noise level was held at $50 \mathrm{~dB}$ SPL and six levels of the tone were presented: 
$35,42,48,55,65$, and $75 \mathrm{~dB}$ SPL. Higher signal and noise levels were avoided so as to minimize adaptation and threshold shift.

Each trial consisted of the subject's responding to the onset of the tone, which was terminated by the response. Stimulus parameters were held constant during blocks of 17 trials. The first two trials of each block were used as practice, and their reaction times were discarded from analysis. The subjects were allowed a short pause, signaled by a rest light, of about $30 \mathrm{sec}$ between each block. There were longer pauses between each group of two or three blocks. Ten or 12 blocks were run in a session, which lasted about $30 \mathrm{~min}$.

Each subject participated in one practice and three experimental sessions. In the first experimental session, all subjects received the 10 constant signal-to-noise ratio conditions in different randomized orders, which were then reversed for the second experimental session. In the third experimental session, all subjects received the 6 constant-noiselevel conditions twice in counterbalanced, randomized order.

\section{Results}

The median, rather than the mean, reaction time for each block was calculated in order to reduce the effect of possible contamination from very short (indicative of anticipation) and very long (indicative of concentration lapses, etc.) reaction times. No significant differences in reaction time were found between the first and second blocks of a stimulus condition in either part of the experiment; nor were there any significant interactions between presentation order and stimulus conditions. Consequently, data from the two blocks for each condition were averaged for the following results.

There was considerable variability between the 11 subjects: median reaction times, averaged over all conditions, ranged from 266 to $343 \mathrm{msec}$.

Figure 1 shows the median reaction time, averaged over the 11 subjects, as a function of the level of the tone, where the signal-to-noise ratio was held constant at -10 and $+10 \mathrm{~dB}$. Analyses of variance confirmed that there was an effect of tone level on reaction time $[F(5,50)=$ $6.21, \mathrm{p}<.05] .^{1}$ Figure 2 shows the median reaction time, averaged over the 11 subjects, as a function of the level of the tone, where the noise level was held constant.

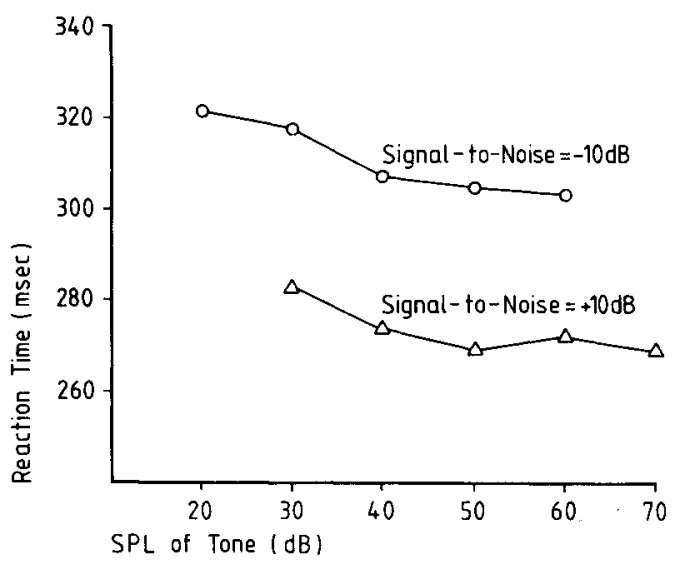

Figure 1. Median reaction time, averaged over 11 subjects, as a function of the sound pressure level of the tone. The level of the noise was either $10 \mathrm{~dB}$ above the level of the tone (signal-to-noise $=-10 \mathrm{~dB}$ ) or $10 \mathrm{~dB}$ below the level of the tone (signal-to-noise $=$ $+10 \mathrm{~dB})$.

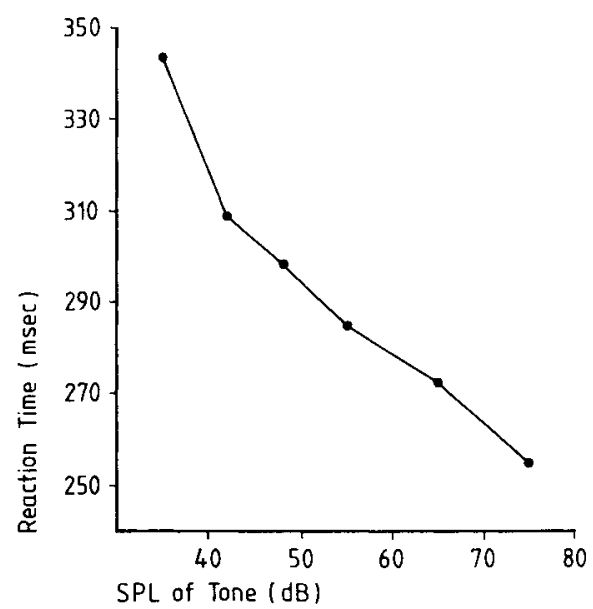

Figure 2. Median reaction time, averaged over 11 subjects, as a function of the sound pressure level of the tone. The level of the noise was fixed at $50 \mathrm{~dB}$ SPL.

These results show that when the signal-to-noise ratio was held constant, reaction time decreased with increasing tone level. The effect, however, as can be seen from a comparison of Figures 1 and 2, is fairly small compared to the effect of increasing tone level when the noise level is held constant.

\section{Discussion}

Since Experiment 1 shows tone level to have an effect on reaction time even when the signal-to-noise ratio is held constant, Weber's law does not describe reaction time to a tone in noise. Such a result was perhaps not unexpected. Raab and Grossberg (1965) found a similar result for reaction time to noise increments. Chocholle and Greenbaum (1966) also obtained the same result for the case of tones masked by tones, although here the result could parallel that found in threshold experiments, since Weber's law does not hold for tones masked by tones (McGill \& Goldberg, 1968; Schöne, 1977).

Qualitatively, the result of Experiment 1 supports Chocholle's hypothesis, since higher tone levels produced shorter reaction times, even when the signal-to-noise ratio was held constant, as predicted. A more convincing test of the hypothesis, however, would be obtained by seeking to relate the reaction times obtained in Experiment 1 to the loudness of the partially masked tones used in the experiment. If the hypothesis is true, reaction time to tonal onset should be a single decreasing function of the judged loudness of the tone. This function should not be dependent on whether a given tonal loudness arose from, for example, a tone of high sound pressure level partially masked by an intense noise or from a low-level tone in the presence of faint noise.

Experiment 1 yielded reaction times to the onset of tones partially masked by noise. Experiment 2 was performed to measure the loudness of the same tones masked by noise. 


\section{EXPERIMENT 2}

\section{Method}

Subjects. Five subjects, all with normal hearing, served in the experiment. None had participated in Experiment 1.

Apparatus. White noise was generated, low-pass filtered $\left(f_{c}=\right.$ $7000 \mathrm{~Hz}$ ) and electronically mixed with the standard $1000-\mathrm{Hz}$ tone. This mixture was fed into one input of the Grason-Stadler electronic switch. A further $1000-\mathrm{Hz}$ comparison tone was produced by a second signal generator, attenuated via a variable attenuator under the control of the subject, and fed into the other input of the switch. The output of the switch was attenuated and presented monaurally through a TDH-49 earphone. The subjects listened in a sound-attenuating chamber.

The switch repeatedly alternated 1.2 -sec presentations of the standard tone and noise combination and the comparison tone with a rise-decay time of $25 \mathrm{msec}$.

Procedure. The subjects listened to the sound with the preferred ear. They were requested to adjust the level of the comparison tone so that it sounded as loud as the tone in the tone and noise mixture. No time limit was set for the adjustment; the subjects signaled when they had completed the match.

The same tone and noise level pairs were used as in Experiment 1. Each pair was presented twice, and the order of presentation was counter-

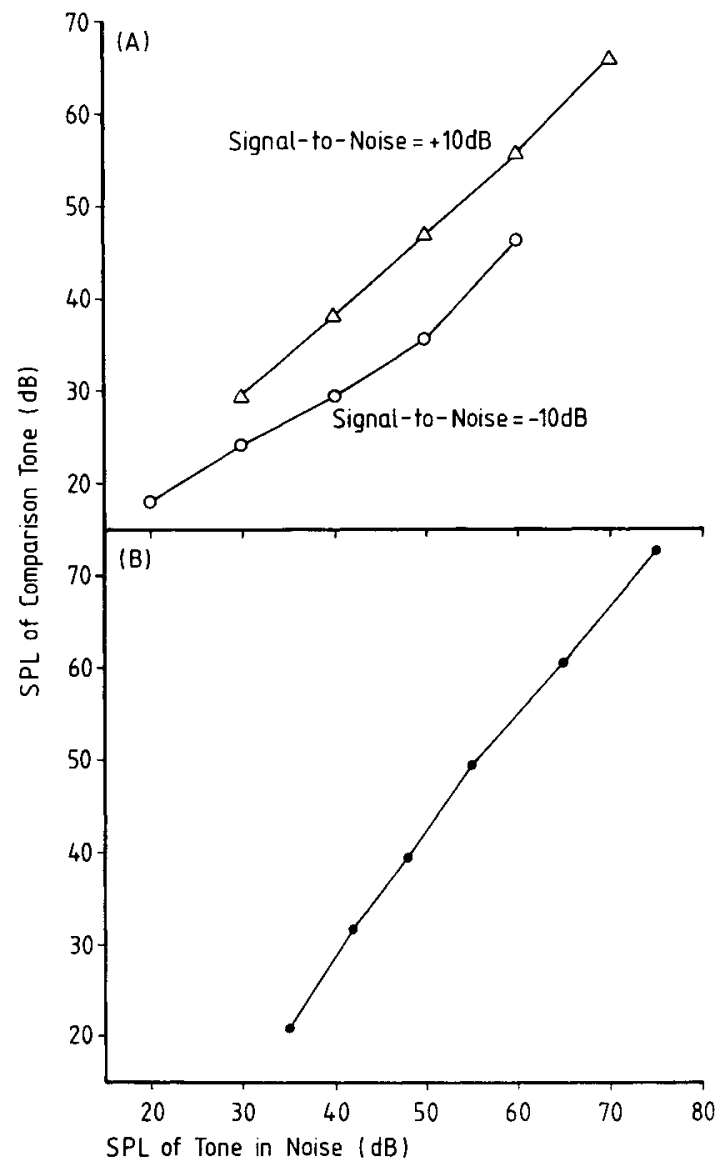

Figure 3. Sound pressure level, averaged over five subjects, of the comparison tone in quiet judged equally loud as a tone partially masked by noise. Levels of the partially masked tone are shown on the abscissa. For results shown in the upper figure (a), the noise level was held at either $10 \mathrm{~dB}$ above or $10 \mathrm{~dB}$ below the level of the masked tone; for results shown in (b), the noise level was held at 50 dB SPL.

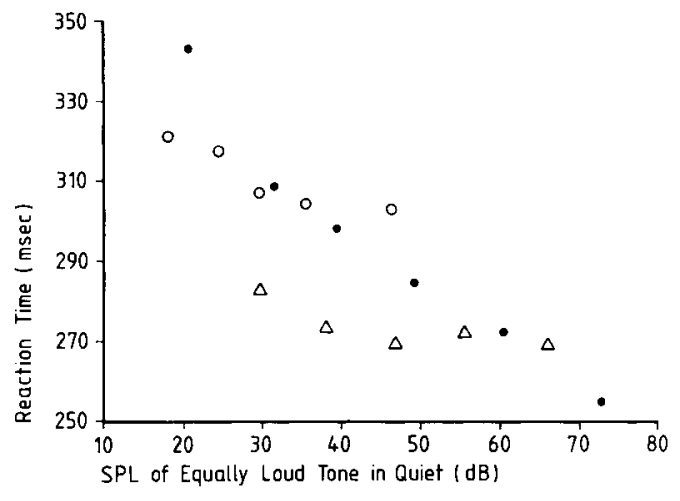

Figure 4. Reaction time to a partially masked tone (i.e., results of Experiment 1) plotted against the sound pressure level of comparison tones judged equally loud as the partially masked tones (i.e., results of Experiment 2). Points from the - 10-dB signal-to-noise ratio conditions are shown as open circles, and from $+10-\mathrm{dB}$ signalto-noise ratio conditions as open triangles. Filled circles depict points from the 50-dB SPL noise level condition.

balanced. If the comparison matches differed by more than $5 \mathrm{~dB}$, a third match was required and the two closest matches were accepted.

\section{Results}

The results of Experiment 2 are presented in Figures $3 \mathrm{a}$ and $3 \mathrm{~b}$. Each point is the average of 10 comparisons ( 2 for each subject).

These results can be compared with those previously reported (Scharf, 1964; Stevens \& Guirao, 1967; Zwicker, 1963). One result of the previous research, that the loudness of a tone in noise increases more rapidly with increasing level than the loudness of the tone in quiet, is clearly evident in Figure $3 \mathrm{~b}$. The results in Figure 3a show a pattern similar to that of comparable results obtained by Stevens and Guirao (1967, Figure 7). Experiment 2, however, generally used lower levels of both tone and noise than was the case in previous research, and comparison in detail is consequently not always possible.

\section{Discussion}

Figure 4 displays the reaction time data of Experiment 1 plotted against the corresponding loudness data of Experiment 2-that is, against the level of the comparison tone in Experiment 2 that was judged as loud as the tone in noise whose onset was reacted to in Experiment 1. It is clear that the data do not fall onto a single function, or approximate to it; rather, the data obtained with the fixed noise level and the two sets obtained with the two fixed signal-to-noise ratios appear to follow three different functions. Reaction time, then, is not simply a function of the loudness of the tone, but, rather, depends in a complex way on the levels of tone and noise presented.

\section{GENERAL DISCUSSION}

Although the qualitative results of Experiment 1 were consistent with the hypothesis that reaction time to a tone 
in noise is functionally related to the loudness of the tone, a more demanding test of the hypothesis failed to uphold it. A similar failure was recently reported by Kohfeld et al. (1981), who discovered that reaction times to equally loud tones (in the quiet) of different frequencies were not equal. Thus, there is no simple relationship between reaction time to a sound and its loudness.

Kohfeld et al. (1981, p. 535) concluded "that signal detection (in reaction time) and stimulus discrimination (in loudness estimation) require different perceptual processes." This investigation certainly supports differentiation of the perceptual processes required to react quickly to a tone and to discriminate loudness. On the other hand, a similar differentiation of the perceptual processes required to react quickly to a sound and to detect a faint sound is suggested by the failure of reaction times to obey Weber's law. It is possible that reacting quickly to a sound involves elements of both discrimination and detection processes, and, indeed, the pattern of results shown in Figure 1 provides tentative support for the notion. Specification of possible composite processes and useful tests of them seems, however, to be a difficult task. In the meantime, the conclusion must be that reaction time to sound does not seem to be simply and straightforwardly related to any other auditory process.

\section{REFERENCES}

Chосноlle, R. (1940). Variation des temps de réaction auditif en fonction de l'intensité à diverses fréquences. Année Psychologique, 41, 65-124.

ChOCHOLle, R. (1975). Les effets de masque, tant totaux que partiels, sur des sons de durée courte ou brève, de sons homolatéraux de longue duree. Journal de Psychologie Normal et Pathologique, 72, 5-22.

Chocholle, R., \& DA Costa, L. (1971). Les temps de réaction à un son pur partiellement masqué contralatéralement par deux autres sons purs simultanés choisis de part et d'autre du premier. Comptes rendus Société de Biologie, 165, 36-41.
Chocholle, R., \& Greenbaum, H. (1966). La sonie de sons purs partiellement masqués. Étude comparatif par une méthode d'égalisation et par la méthode des temps de réaction. Journal de Psychologie Normal et Pathologique, 63, 385-414.

Emmerich, D. S., Pitchford, L. J., \& Becker, C. A. (1976). Reaction time to tones in tonal backgrounds and a comparison of reaction time to signal onset and offset. Perception \& Psychophysics, 20, 210-214.

Hawkins, J. E., \& Stevens, S. S. (1950). The masking of pure tones and of speech by white noise. Journal of the Acoustical Society of America, 22, 6-13.

KeMP, S., \& IRWIN, R. J. (1979). Reaction time to the start and end of weak signals in noise. Psychological Research, 40, 367-376.

Kohfeld, D. L., Santee, J. L., \& W Wllace, N. D. (1981). Loudness and reaction time: I. Perception \& Psychophysics, 29, 535-549.

LuCE, R. D., \& GREEN, D. M. (1972). A neural timing theory for response times and the psychophysics of intensity. Psychological Review, 79, 14-57.

McGill, W. J., \& Goldberg, J. P. (1968). Pure-tone intensity discrimination and energy detection. Journal of the Acoustical Society of America, 44, 576-581.

RAAB, D. H., \& GrossberG, M. (1965). Reaction time to changes in the intensity of white noise. Journal of Experimental Psychology, 69, 609-612.

SANTEE, J. L., \& Kohfeld, D. L. (1977). Auditory reaction time as a function of stimulus intensity, frequency, and rise time. Bulletin of the Psychonomic Society, 10, 393-396.

ScharF, B. (1964). Partial masking. Acustica, 14, 16-23.

ScHöne, P. (1977). Nichtlinearitäten im Mithörschwellen-Tonheitsmuster von Sinustönen. Acustica, 37, 37-40.

Stevens, S. S., \& Guirao, M. (1967). Loudness functions under inhibition. Perception \& Psychophysics, 2, 459-465.

ZWICKER, E. (1963). Über die Lautheit von ungedrosselten und gedrosselten Schallen. Acustica, 13, 194-211.

\section{NOTE}

1. For this analysis, reaction times were averaged over the two signalto-noise ratios by taking the lowest tone level as the lowest for each signal-to-noise ratio condition $(20 \mathrm{~dB}$ for the $-10-\mathrm{dB}$ and $30 \mathrm{~dB}$ for the $+10-\mathrm{dB}$ signal-to-noise ratio condition) and so on, for the five levels.

(Manuscript received August 22, 1984; accepted for publication August 23, 1984.) 